\title{
Product Platforms in Industrialized House Building - Information Modeling Method
}

\author{
Djordje POPOVIC $^{\mathrm{a}, 1}$, Dag RAUDBERGET ${ }^{\mathrm{a}}$ and Fredrik ELGH ${ }^{\mathrm{a}}$ \\ ${ }^{a}$ Department of Industrial Product development, Production and Design, School of \\ Engineering, Jönköping University, Sweden
}

\begin{abstract}
There is a demand on the current markets of industrialized house building for higher product design flexibility and customization. One of the success factors in addressing this challenge efficiently is the formalization and use of product platforms through information technology applications. However, there is a lack of knowledge on how product platforms and their use should be modeled to support the development of information technology applications. The aim of this paper is therefore, to increase the knowledge on information modeling of product platforms and their use in the industrialized house building design process. The available information modeling methods were identified and analyzed using literature review while considering the contextual criteria of industrialized house building. An information modelling method for product platforms and their use in the industrialized house building design process is proposed. The information modeling rationale is synthesized using the design platform modeling and the information delivery manual modeling. The former is a PLM-oriented while the latter is a BIMoriented information modeling method. The proposed information modeling method is composed of three parts: product platform information model, process maps and exchange requirement specification. Future work should aim for the validation of the proposed information modeling method by application on empirical data in a case study.
\end{abstract}

Keywords. PLM, BIM, building information management, product lifecycle management, mass customization

\section{Introduction}

Product platforms have been a topic of research in industrialized house building (IHB) for more than a decade [1] and since then are established as one of the central approaches to manage a balance between commonality and distinctiveness of products and processes in this context [2]. Predefined product platform assets are used in house building projects by means of design process support methods, where customized product variants are specified [3]. For the description of the product platforms and their use, Jansson, et al. [3] adjusted the phenomena model originally developed by Meyer and Lehnerd [4]. However, to realize such ideas, product platforms must be formalized and implemented in IT applications in order to manage information exchange between different design and engineering disciplines involved in a design process, such as architectural design and structural engineering [5]. Formalized product platforms and their use is covered in the

\footnotetext{
${ }^{1}$ Corresponding Author. djordje.popovic@ju.se
} 
literature desribing IT application case studies [6-9] and developed knowledge-based engineering tools [10-12].

The main prerequisite that facilitates the development of IT applications, is information modelling [13, 14]. The current information modeling research in the context of IHB shows examples of product structure modeling [15-17], process modeling $[18,19]$ and requirements modeling [20]. Although, product structure, processes and requirements are inseparable parts of product platforms and their use, separately their information models do not cover the scope of product platforms. Information models that can elaborate this phenomenon in a formal way and support the development of IT system solutions are missing in the literature. Moreover, there is a lack of knowledge in the current literature regarding information modeling methods that would bridge the gap between the conceptual phenomenon descriptions and the realized IT applications of product platforms and their use in the IHB design process [21]. The aim of this paper is therefore, to increase the knowledge on information modeling of product platforms and their use in the IHB design process. To accomplish the aim of the study following objectives are formulated. Objective 1 is to identify and compare the existing information modeling methods and tools. Objective 2 is to synthesize and propose an information modelling method for product platforms and their use in the IHB design process.

\section{Theoretical background}

\subsection{Industrialized house building}

The industrialization of house building did not only imply the shift from on-site assembly to off-site manufacturing but also the shift from project to product and process orientation [2]. Different levels of technical and process predefinitions used to create offerings for certain markets led to a formulation of different production strategies in IHB [22]. Therefore, the central aspect of IHB became the development of robust technical systems based on the market, legal, production and supply chain requirements and constraints, i.e. building systems [2]. The product distinctiveness and adaptability to the contingencies, is enabled by applying common building systems and their design bandwidth in the configuration and customization processes of multi-family building projects [3] in an engineer-to-order (ETO) design process. On the other hand, some single-family house builders use their building systems and optimized off-site manufacturing to develop predefined catalogue designs according to the forecast for niche markets [22]. The select-a-variant (SV) design process is almost completely performed before the customer enters the supply chain. The IHB companies, can therefore be differentiated on whether they rely more on process (ETO) or product (SV) standardization after the customer entry in the supply chain [22]. In between these two opposite strategies (SV and ETO), house builders can engage in the configure-to-order (CTO) and modify-to-order (MTO) design processes, which best fit the mass customized house building [23]. Components modules in such offerings vary between standard (SV), variant (CTO), flexible (MTO) and unique (ETO) [8, 24, 25].

The documentation and formalization of technical and process knowledge led to the formation of product platforms in IHB [3]. Inspired by automotive and other make-toorder industries [26], further design flexibility and process efficiency was achieved by some IHB companies through the application of modularization principles when developing product platforms [27]. However, offering high design flexibility through an 
efficient exploration of the building system design bandwidth while conforming to other contingent requirements and constraints necessitates formalization of engineering resources and processes as part of the product platform. These engineering resources should enable parametric modeling of the product geometry an behavior [8, 28].

Information technology (IT) applications are enablers of efficient implementation of product platforms in an IHB design process [2, 5]. It is associated with building information modeling (BIM) which Sacks, et al. [28] define as "a modeling technology and associated set of processes to produce, communicate, and analyze building models". Industry foundation classes (IFC) schema is a result of an effort to enhance the interoperability between different BIM tools by encompassing object, attribute and relation definitions across the product lifecycle in one open and consistent data representation standard (ibid.). However, this raises an issue of data redundancy as a specific use of a model in a BIM tool requires only partial model data [29]. To address this issue model view definitions are developed (ibid.). Integration of various BIM tools and platforms into an environment where product data and workflows of all product lifecycles, including the product development processes that take place before the customer order decoupling point, is suggested for IT development [28]. In the manufacturing industries, product lifecycle management (PLM) systems are used for this purpose [30].

\subsection{Product platform use}

The concepts of product platforms and their use in IHB was studied by Jansson, et al. [3]. The authors collected empirical data regarding platform documentation from two case companies and analyzed what are the product platform assets reused in the building projects. Each building project was a realization of a specific product variant, i.e. multifamily houses. The starting point of investigation was a product platform use description from Meyer and Lehnerd [4] where a set of four platform assets are used in the development of product families across different market segments and price tiers. This model is valid for the manufacturing industries where the whole products and configuration options are predefined, and where the product variants are made-to-order. In the context of IHB, product platform assets are used directly in the building projects for the product specification without previously developed product families. The specific product variants are customized using support methods for product platform use: design planning, collaborative design, design optimization and requirements iterations [3]. However, an exception is the single-family house market where companies release predefined catalogue models [22] in select-a-variant and configure-to-order specification process. Another description of product platform use in the IHB design process is given by Bonev, et al. [23]. The description is based on the combination of the axiomatic design application on the product family development [26] and the upstream flow of constraints between different product views in the building project [17]. The product platform use is described through the intersection of external requirements with internal constraints throughout the specification process. The studies of Bonev, et al. [23] and Jansson, et al. [3] conceptually describe the product platforms and their use in the IHB design process, however the modeling of products and processes including support methods, constraints and requirements remains unclear. 


\subsection{Design modeling research approach}

A prerequisite for platform modelling is the phenomenological understanding of a product platform. Duffy and Andreasen [31] discuss different model classes in relation to engineering design and divide models into three classes: phenomenon models, information models and computer models (Figure 1). These modelling classes provide a relation between different models and its underlying reality. Modeling the reality is a way to simplify and clarify aspects related to product platforms. Phenomena models are of a descriptive nature that reflect design practice. These are primarily based on observations and analyses of the tools employed by designers and the "reality" of design. Phenomena models can be developed in more detail as information models that, in turn, support the development of computational models.

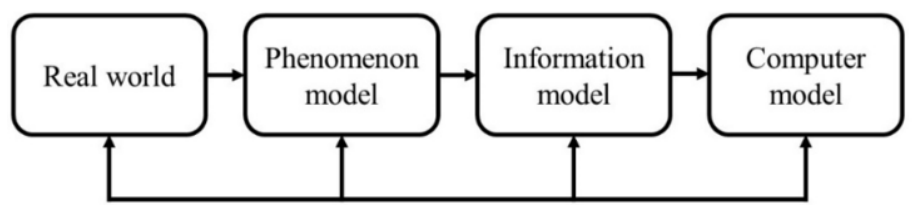

Figure 1. Design modeling research approach (Duffy and Andreasen [30])

Understanding a phenomenon within will not necessarily lead to improvements in industrial practice. The models are therefore seen as prescriptive "alien" models that are used to alter the native way of working. Furthermore, all models are dependent on the chosen theoretical framework. The model is therefore a view of the phenomena, building on an understanding of the object of study, a theory or specific modelling principle. This implies that a specific theory will lead to a certain perception and representation of the platform.

\section{Method}

The study reported in this paper fits within the design research methodology (DRM). The DRM [32] proposes four stages of the research process: research clarification (RC), the first descriptive study (DS-I), prescriptive study (PS) and the second descriptive study (DS-II).

In the RC stage, the goals that the research is expected to fulfill are defined. Other objectives are to define the focus of the project, main research questions and problems, the relevant disciplines and areas to be reviewed and the area of scientific and practical contribution. In order to increase the understanding of the current state in the area of interest and its success factors, the DS-I stage is conducted by reviewing the literature about empirical research, conducting the empirical research and through reasoning. In the PS stage, the success factors and criteria from the DS-I stage are used to steer the logic and the synthesis of the support artefact meant to improve the existing situation. The support is developed to address these key factors in a systematic way and an evaluation plan is developed to be used in DS-II stage. In the DS-II stage the focus lies on the testing and evaluation of the support artefact to identify if it can be used for the task for which it was developed for and if it has the expected effect on the criteria and 
success factors identified in the DS-I stage. Therefore, possible improvements for the support might be identified.

This study represents the PS stage of the DRM framework. The set of criteria for the support (Section 1.1) as an input to the PS stage, are identified in the DS-I stage. The method conducted consists of three parts: a literature review, analysis of the relevant information modeling methods and tools, and synthesis of the information modeling method that suits product platforms and their use in an IHB design process, i.e. fulfill the DS-I criteria.

The first step of the literature review part was the identification of information modeling methods reported in the IHB literature state of the art. In the second step, another set of articles was identified through the backward citation search. These articles were referred to in connection to the identified information modeling methods from the IHB literature. Some of the articles from the second set are review articles that cover other information modeling methods not yet used in IHB context. In the third step, forward citation search was applied on the articles from the second set which were cited in a high number of other articles. In this way it was possible to identify newest relevant articles about information modeling methods.

In the second part of the method, the identified information modeling methods were analyzed and compared. The comparison was made based on the criteria established in the DS-I stage of the DRM framework. Finally, the analysis and comparison of the identified methods enabled the last part of the research method, i.e. synthesis of an information modeling method for product platforms and their use in an IHB design process.

\section{Results}

\subsection{State of the art on information modeling in IHB}

Object-oriented information models describing products, using unified modeling language (UML) notation were presented in several publications aimed at developing IT applications. Liu, et al. [33] modeled product information to describe the building information extraction from BIM models. The extraction is the first part of the automated design and planning prototype system for boarding of light-frame buildings. Similarly, Montali, et al. [34] develop a product model based on the design and manufacturing knowledge gathered on prefabricated façades. Ramaji and Memari [16] propose a product architecture model (PAM) to be used as an object-oriented information model serving as a repository of product information such as structure, property attributes and interactions for the multi-story modular building systems. Frutos and Borenstein [35] presented a framework for the development of an agile system for information exchange between a building company and customers that enables product customization. The central part of the framework is a product model.

An example of UML modeling is presented in the product configuration system development framework [36]. Object-oriented models are formalization of product range knowledge collected and documented using product variant master (PVM) phenomena modeling approach. Modeling of product ranges using PVM was presented in several studies in the IHB context [15, 17, 37], however without presenting formalized information models. Another modeling approach was presented in a requirement management framework as a support for the modeling of energy requirements that are 
derived from building codes, standards and local conditions [20]. The framework includes phenomena modeling using axiomatic design and information modeling using requirement-driven product modeling [38].

Formalization of process knowledge was studied and represented using IDEF0 notation [19] and business process modeling notation (BPMN) [18, 34]. Persson, et al. [19] investigated information management practices in six Swedish IHB companies and identified three areas to consider before investing in an IT application development: formal description of processes, product range description and IT strategy. Ramaji, et al. [18] demonstrated a development of process maps for the conventional modular building design process, as the part of an extended information delivery manual (IDM) method. Likewise, Montali, et al. [34] modeled a design process that incorporates optimization using custom-built digital tools.

Through backward and forward citation search two product platform modeling approaches not yet applied to the IHB context were identified. These are the Design platform (DP) modeling method [39] and product platform development framework combining enhanced Function-Means (EF-M) modeling, Configurable Component (CC) modeling and Set-based Concurrent Engineering (SBCE) [40].

\subsection{Information modeling methods}

Based on the literature review, product and process modeling methods were identified and are briefly explained below based on the analysis. The comparison and the choice of methods for the synthesis of the modeling method for product platforms and their use in design processes is summarized and discussed.

In the context of BIM, the development of model view definitions is supported by the IDM method suggested by buildingSMART International [28]. Three main parts of the IDM method are BPMN process maps, information model and exchange requirement specification (ERS) that describes how instantiated objects from the information model are used in the process. Therefore, IDM aims to facilitate the work of BIM application developers and end-users through the description of these three parts.

In their recent study, Ramaji, et al. [18] propose extension of the IDM method adjusted for the design of multistory modular buildings. The authors address the need for product information models that combine and balance the project focus of the conventional construction and product/process focus of manufacturing industries. Product architecture model (PAM) is developed to be used as an information model that serves as a repository of multistory modular buildings information such as hierarchy structure, properties, attributes and interactions [16]. It has an object-oriented modeling rationale using UML notation and aims at decomposition of the generic building structure at different hierarchical levels and connecting each structure object with generic attributes.

A common approach for controlling product families is to use a product configuration system. These are mainly used to customize a product to meet specific needs and constraints of a customer. Configurators rely on a detailed knowledge of the product platform and on design rules that can deduct a valid configuration for a specific set of input parameters. Configurators are often prepared by studying the components and structures of existing products and their lifecycle systems. An example of the preparation process is given by Hvam, et al. [36] through the Product Variant Master (PVM) method. The preparation of a product configuration system is based on an existing physical architecture and the product range described through different views 
such as, customer, engineering part and supply chain. The PVM method is used for the analysis and visual modeling with the goal of reducing the number of unique components, predefinition of all module variants and standardizing the interfaces. The knowledge collected through PVM is further formalized using object-oriented modeling and UML notation, and finally programmed into a product configuration system [36].

Functionality is a key concept for knowledge about products and systems and several authors have touched upon the idea of using functions and functional couplings for the product platform modelling. Johannesson and Claesson [41] present the CC modeling technique to support the development of product platforms with functional modelling. As opposed to the development of a single product, the goal is not to arrive at one final design, rather to develop the platform from which several individual members of the product family can be instantiated.

In their recent publication, Johannesson, et al. [40] propose a framework for the development of flexible product platforms (FPPD). The first part of the framework is platform preparation where platform objects are modeled using EF-M and CC modeling techniques. The second part of the framework is platform execution where SBCE processes are used. The aim of SBCE proceses is to enable an early design screening of sets of feasible solutions and gradual narrowing down of choice towards detail design phase by introduction of additional functional requirements and constraints.

EF-M modelling [42] extends the initial function-means technique for functional decomposition and concept generation [43]. The initial method models functional requirements (FR), i.e. the solution-driving requirements, and the means, expressed as design solutions (DS) that deliver the desired functionality. The enhanced method introduces concepts that also capture the solution-restraining requirements, so-called constraints (C), and the relations between FRs, DSs and Cs in the same hierarchical model. In this way product platform modular bandwidth is captured. The scalable bandwidth is modeled with the $\mathrm{CC}$ technique by defining parameters connected to the modules and interfaces and by that describe different features of a platform, its interactions and constraints. The EF-M can be regarded as a phenomenon modeling method while information modeling is done using CC. Both EF-M and CC led to a development of a configurable component modeler (CCM) configuration system.

André, et al. [39] developed DP modeling method, where compared to previously presented product platform modeling approaches (PCSD and FPPD), a step further is taken to even include the engineering resources in the model, referred to as design assets in the rest of the paper. Hence, a coherent approach to product platforms is developed, applicable to industries susceptible to high product customization, i.e. engineer-to-order (ETO) manufacturing industries.

The purpose of the DP modeling method is therefore to support generic product and process modeling when it is not possible to predefine whole products and its modular composition as in the traditional component-based product platforms developed in the make-to-order manufacturing industries [44]. In such case, the design solutions of products and some of its parts that are subjected to customization are defined during the specification processes after the customer order decoupling point. Up until the point of design solution specification, the products and/or its parts can be described using design assets such as assessment, synthesis and geometry resources, constraints, processes and projects [45]. A DP phenomena model is shown in Figure 2. The DP modeling rationale is based on object-oriented modelling and the UML notation. 


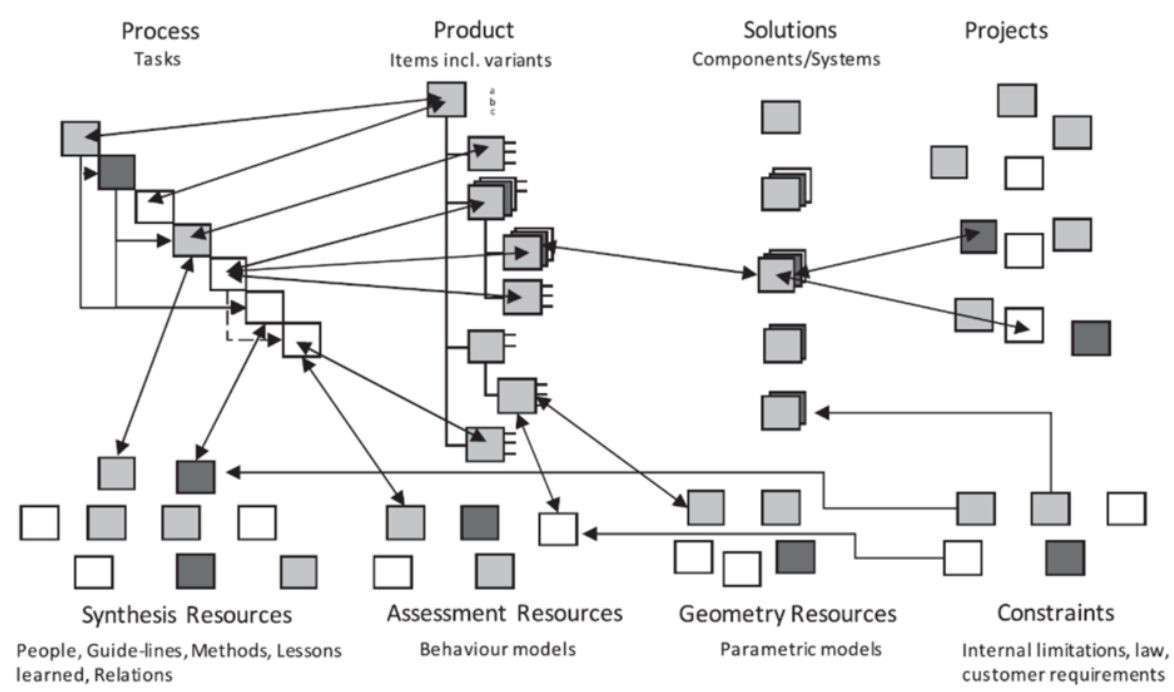

Figure 2. Design platform phenomenon model (André et al. [38])

\subsection{Proposed information modeling method}

According to the criteria of the IHB context, the DP is the most suitable modeling method for product platforms (Table 1). It enables modeling of the generic product structures and relationships between them. By doing so it is possible to model the modular bandwidth of a building system. By connecting different design asset classes to product structure classes, it is possible to enrich the product platform objects that are instantiated to be used in parts of a design process. For example, if a certain product structure cannot be described with the solution at the beginning of the design process it can be described with a parametric model (geometry resource) and a performance analysis guideline (assessment resource). To enable modeling of the product platforms and their use in a IHB design process, the DP modeling method can be paired with BPMN process maps and ERS from the IDM method (Figure 3).

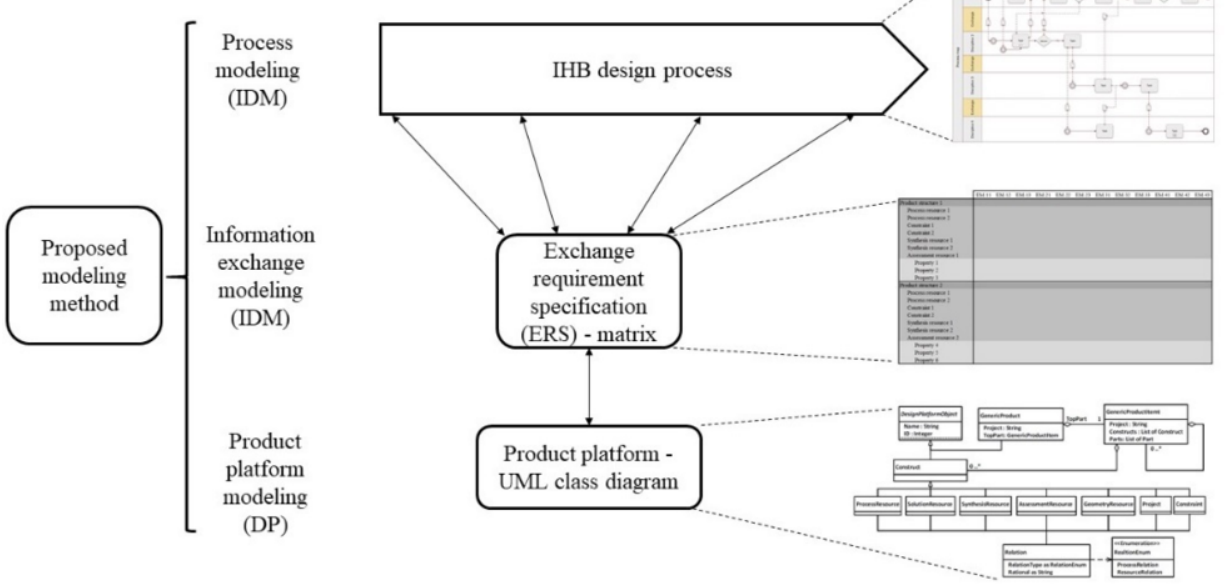

Figure 3. Proposed information modeling method for the product platform use in the IHB design process 
ERS is a matrix-based tool that describes which product platform model objects are used in BPMN process maps and when via exchange models. Exchange models are represented as columns while product platform objects and corresponding attributes are represented as rows. Exchange models are visualized in BPMN process maps where they connect process activities and different design disciplines [18].

\section{Discussion}

Varying external requirements and constraints meet internal requirements and constraints, and thereby affect the level of product design predefinition. Before the product variant specification is initiated for a customer, products can only partly be predefined with some design solutions. During product variant specification, engineering design is needed to obtain a solution for a product variant. Therefore, a single product variant can be mix of components and assemblies that were created through ETO, MTO, CTO and/or SV design processes [8, 24, 25]. Moreover, resulting design solutions are a mix of modular and integral architectures.

If compared to the IDM as presented by Ramaji, et al. [18], PAM is replaced with a DP modeling method (Table 1). The PAM objects cover structural design of modular multistory buildings while the mechanical, electrical and plumbing (MEP) system designs that often require unique (ETO) solutions are not modeled. Up until the point of defining the solution, DP enables modeling of such unique systems through design assets. A sole component focus of PAM does not suffice to model product platforms. PAM, having the scope of BIM, models product structure objects with constraints as attributes hence does not capture different design assets as the PLM-oriented DP modeling method does.

The DP modeling method complements IDM and vice versa. In a DP model, standardized processes are modeled as object classes. However, there is a lack of process representation and visualization where it would be clear how the instantiated objects from a DP model are used, i.e. the use of product platforms. Contribution of the IDM method to this issue is the process modeling with BPMN process maps and product platform use with an ERS.

Table 1. Comparison between information modeling methods

\begin{tabular}{ccccc}
\hline Modeling & & UML notation & & EF-M and CC \\
\cline { 2 - 5 } characteristics & PAM & DP & PCSD & FPPD \\
\hline Product type & Modular & Modular, scalable and & Modular & Modular and \\
& & customized & scalable \\
Design process type & CTO & ETO, MTO, CTO, SV & CTO & CTO, MTO \\
Product structure & Yes & Yes & Yes & Yes \\
Design assets & No & Yes & No & No \\
Requirements $/$ & Yes & Yes & Yes & Yes \\
constraints & & & & \\
\hline
\end{tabular}

The PCSD framework [36] is also based on object-oriented information modeling where it is possible to model the modular bandwidth of the configurable products, such as cars. Such approach is applicable for some housing concepts however, requires a ful predefinition of high level assemblies in the product structure, such as volumetric elements of the houses. Therefore, the lack of possibility to model the scalable bandwidth is the main reason not to choose modeling rationale of the PCSD framework. 
The main goal of the flexible product platform development framework [40] is to enable modular and scalable bandwidth modeling using EF-M and CC, respectively. The product platform use is described through the SBCE processes. However, the modeling rationale behind EF-M and $\mathrm{CC}$ that aims at fully modular product architectures does not suit products such as houses. The one-to-one matching between the design solutions and functional requirements throughout the product structure does not fit often integral architectures of house elements. For example, an exterior wall as part of a building system can be regarded as a design solution that fulfills several functional requirements.

The aim of IDM method is to support the development of MVDs that ultimately should delimit and partition IFC schema and by that enable structured and efficient information exchange between BIM tools [28]. However, the focus application area of $\mathrm{BIM}$ is conventional project-oriented house building. Frequent arguments are currently made that the IHB companies should consider developing PLM systems due to the increasing product and process orientation $[23,30]$. Formalization of a product platform in a PLM system is what the DP modeling method supports. By combining IDM and DP in the proposed information modeling method, the scope of modeling is extended to include even product development and predefinition processes before the projects are initiated. These are the first phases of PLM [46].

Regarding the practical implication of the proposed information modeling method, implementing it in an IHB company does not directly result in an IT application. However, it is a step that preceeds and supports a development of an IT application through information modeling [31]. The scientific contribution of this paper is an increased knoweldge of how product platforms and their use in the IHB design process, as described with the phenomena models of Bonev, et al. [23] and Jansson, et al. [3] can be modeled.

\section{Conclusions}

The conducted prescriptive study, based on the literature review as presented in the paper, resulted in a synthesized information modeling method for product platforms and thier use in the IHB design process. The method is an alteration of IDM as presented by Ramaji, et al. [18]. The information modeling of product platforms, i.e. hierarchically structured parts and available design assets, is done according to the DP modeling method. From the IDM method, the BPMN process maps can be used to model design processes and an ERS to model the connection between a product platform information model and process maps, hence describing the product platform use. Such a method suits best the criteria of the IHB context. Compared to BIM, the modeling scope of the proposed method includes the product development and predefinition processes taking place before/aside the projects, therefore supporting PLM system implementation. Suggested future work is conducting the DS-II stage of the DRM and test the proposed information modeling method in an IHB case study. An empirical study should be conducted to collect the data and information regarding design process, product platform and its use using interviews and workshops with the domain experts. The method should be used to model and display this data. Finally, the obtained models should be validated and evaluated through a workshop with the domain experts. 


\section{Acknowledgements}

This research project is part of the graduate school ProWOOD which is a collaboration between School of Engineering at Jönköping University, Linnaeus University, Nässjö Träcentrum, several companies, and a research institute. The graduate school is financially supported by The Knowledge Foundation (KK-stiftelsen).

\section{References}

[1] V.S. Veenstra, J.I.M. Halman, and J.T. Voordijk, A methodology for developing product platforms in the specific setting of the housebuilding industry, Research in Engineering Design, vol. 17, no. 3, 2006, pp. 157-173.

[2] J. Lessing, L. Stehn, and A. Ekholm, Industrialised house-building - Development and conceptual orientation of the field, Construction Innovation, vol. 15, no. 3, 2015, pp. 378-399.

[3] G. Jansson, H. Johnsson, and D. Engström, Platform use in systems building, Construction Management and Economics, vol. 32, no. 1-2, 2014, pp. 70-82.

[4] M.H. Meyer and A.P. Lehnerd, The power of product platforms, Simon and Schuster, New York, USA, 1997.

[5] L. Malmgren, "Industrialized construction-explorations of current practice and opportunities," Faculty of Engineering and Division of Structural Engineering, Lund, Sweden, 2014.

[6] J. Mukkavaara, G. Jansson, and T. Olofsson, Structuring information from BIM: A glance at bills of materials, In: 35th International Symposium on Automation and Robotics in Construction, 2018: I.A.A.R.C.

[7] P. Jensen, T. Olofsson, and H. Johnsson, Configuration through the parameterization of building components, Automation in Construction, vol. 23, 2012, pp. 1-8.

[8] S. Khalili-Araghi and B. Kolarevic, Variability and validity: Flexibility of a dimensional customization system, Automation in Construction, vol. 109, 2020.

[9] F. Bianconi, M. Filippucci, and A. Buffi, Automated design and modeling for mass-customized housing. A web-based design space catalog for timber structures, Automation in Construction, vol. 103, 2019, pp. 13-25.

[10] J. Montali, M. Overend, P.M. Pelken, and M. Sauchelli, Knowledge-Based Engineering in the design for manufacture of prefabricated façades: current gaps and future trends, Architectural Engineering and Design Management, vol. 14, no. 1-2, 2018, pp. 78-94.

[11] H.M. Said, T. Chalasani, and S. Logan, Exterior prefabricated panelized walls platform optimization, Automation in Construction, vol. 76, 2017, pp. 1-13.

[12] S. Isaac, T. Bock, and Y. Stoliar, A methodology for the optimal modularization of building design, Automation in Construction, vol. 65, 2016, pp. 116-124.

[13] T.D. Brunoe and K. Nielsen, Data-Driven Product Family Modeling with Feedback, In: The 9th World Mass Customization \& Personalization Conference, Aachen, Germany, 2018: Springer International Publishing, pp. 469-478.

[14] A.H. Duffy and F. O'Donnell, A design research approach, In N. H. Mortensen and J. Sigurjonsson, (eds.). Critical Enthusiasm: Contribution to Design Science, Tapir, Trondheim, Norway, 1999, pp. 3340.

[15] F. Wikberg, T. Olofsson, and A. Ekholm, Design configuration with architectural objects: Linking customer requirements with system capabilities in industrialized house-building platforms, Construction Management and Economics, vol. 32, no. 1-2, 2014, pp. 196-207.

[16] I.J. Ramaji and A.M. Memari, Product Architecture Model for Multistory Modular Buildings, Journal of Construction Engineering and Management, vol. 142, no. 10, 2016.

[17] L. Malmgren, P. Jensen, and T. Olofsson, Product modeling of configurable building systems - A case study, Electronic Journal of Information Technology in Construction, vol. 16, 2011, pp. 697-712.

[18] I.J. Ramaji, A.M. Memari, and J.I. Messner, Product-Oriented Information Delivery Framework for Multistory Modular Building Projects, Journal of Computing in Civil Engineering, vol. 31, no. 4, 2017.

[19] S. Persson, L. Malmgren, and H. Johnsson, Information management in industrial housing design and manufacture, Electronic Journal of Information Technology in Construction, vol. 14, 2009, pp. 110-122.

[20] G. Jansson, J. Schade, and T. Olofsson, Requirements management for the design of energy efficient buildings, Journal of Information Technology in Construction, vol. 18, 2013, pp. 321-337. 
[21] H. Eriksson and E. Emilsson, Platforms for enabling flexibility at two construction companies, In: ISARC. Proceedings of the International Symposium on Automation and Robotics in Construction, 2019: I.A.A.R.C, pp. 348-355.

[22] H. Johnsson, Production strategies for pre-engineering in house-building: Exploring product development platforms, Construction Management and Economics, vol. 31, no. 9, 2013, pp. 941-958.

[23] M. Bonev, M. Wörösch, and L. Hvam, Utilizing platforms in industrialized construction: A case study of a precast manufacturer, Construction Innovation, vol. 15, no. 1, 2015, pp. 84-106.

[24] M. Schoenwitz, A. Potter, J. Gosling, and M. Naim, Product, process and customer preference alignment in prefabricated house building, International Journal of Production Economics, vol. 183, 2017, pp. 7990.

[25] P. Jensen, "Configuration of platform architectures in construction," Luleå tekniska universitet, Luleå, Sweden, 2014.

[26] J. Jiao, T.W. Simpson, and Z. Siddique, Product family design and platform-based product development: a state-of-the-art review, Journal of Intelligent Manufacturing, vol. 18, no. 1, Feb 2007, pp. 5-29.

[27] P. Jensen, H. Lidelöw, and T. Olofsson, Product configuration in construction, International Journal of Mass Customisation, vol. 5, no. 1, 2015, pp. 73-92.

[28] R. Sacks, C. Eastman, G. Lee, and P. Teicholz, BIM handbook: a guide to building information modeling for owners, designers, engineers, contractors, and facility managers, John Wiley \& Sons, 2018.

[29] M. Venugopal, C.M. Eastman, R. Sacks, and J. Teizer, Semantics of model views for information exchanges using the industry foundation class schema, Advanced Engineering Informatics, vol. 26, no. 2, 2012, pp. 411-428.

[30] C. Boton, L. Rivest, D. Forgues, and J.R. Jupp, Comparison of shipbuilding and construction industries from the product structure standpoint, International Journal of Product Lifecycle Management, vol. 11, no. 3, 2018, pp. 191-220.

[31] A. Duffy and M. Andreasen, Enhancing the evolution of design science, In: Proceedings of ICED, 1995, vol. 95 , pp. 29-35.

[32] L.T.M. Blessing and A. Chakrabarti, DRM, a design research methodology, Springer London, 2009.

[33] H. Liu, G. Singh, M. Lu, A. Bouferguene, and M. Al-Hussein, BIM-based automated design and planning for boarding of light-frame residential buildings, Automation in Construction, vol. 89, 2018, pp. 235-249.

[34] J. Montali, M. Sauchelli, Q. Jin, and M. Overend, Knowledge-rich optimisation of prefabricated façades to support conceptual design, Automation in Construction, vol. 97, 2019/01/01/ 2019, pp. 192-204.

[35] J.D. Frutos and D. Borenstein, Object-oriented model for customer-building company interaction in mass customization environment, Journal of Construction Engineering and Management, vol. 129, no. 3, 2003, pp. 302-313.

[36] L. Hvam, N.H. Mortensen, and J. Riis, Product customization, Springer Berlin Heidelberg, Germany, 2008.

[37] A. Kudsk, L. Hvam, C. Thuesen, M.O. Grønvold, and M.H. Olsen, Modularization in the construction industry using a top-down approach, Open Construction and Building Technology Journal, vol. 7, 2013, pp. 88-98.

[38] J. Malmqvist, Implementing requirements management: A task for specialized software tools or PDM systems?, Systems Engineering, vol. 4, no. 1, 2001, pp. 49-57.

[39] S. André, F. Elgh, J. Johansson, and R. Stolt, The design platform - a coherent platform description of heterogeneous design assets for suppliers of highly customised systems, Journal of Engineering Design, vol. 28, no. 10-12, 2017/12/02 2017, pp. 599-626.

[40] H. Johannesson, J. Landahl, C. Levandowski, and D. Raudberget, Development of product platforms: Theory and methodology, Concurrent Engineering, vol. 25, no. 3, 2017, pp. 195-211.

[41] H. Johannesson and A. Claesson, Systematic product platform design: A combined function means and parametric modeling approach, Journal of Engineering Design, vol. 16, no. 1, 2005, pp. 25-43.

[42] P. Schachinger and H.L. Johannesson, Computer modelling of design specifications, Journal of Engineering Design, vol. 11, no. 4, 2000, pp. 317 - 329.

[43] K.H. Svendsen and T.C. Hansen, Decomposition of mechanical systems and breakdown of specifications, In: Proceedings of ICED 1993, The Hague, The Netherlands, 1993.

[44] S. André and F. Elgh, Modeling of transdisciplinary engineering assets using the design platform approach for improved customization ability, Advanced Engineering Informatics, vol. 38, 2018, pp. 277290.

[45] F. Elgh, J. Johansson, R. Stolt, M. Lennartsson, T. Heikkinen, and D. Raudberget, Platform Models for Agile Customization - What's Beyond Modularization?, In: International Conference on Transdisciplinary Engineering, Modena, Italy, 2018. pp. 371-380.

[46] H.P.L. Bruun, N.H. Mortensen, U. Harlou, M. Wörösch, and M. Proschowsky, PLM system support for modular product development, Computers in Industry, vol. 67, 2015, pp. 97-111. 